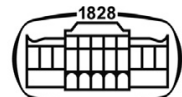

AKADÉMIAI KIADÓ

European Journal of Microbiology and Immunology

$10(2020) 3,172-177$

Dol:

$10.1556 / 1886.2020 .00026$

(c) 2020 The Authors

\section{ORIGINAL RESEARCH} PAPER

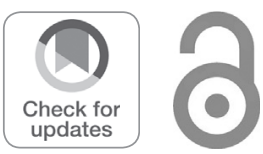

\title{
Enteric pathogens in German police officers after predominantly tropical deployments - A retrospective assessment over 5 years
}

\author{
MATTHIAS HALFTER ${ }^{1}$, ULRICH MÜSELER ${ }^{2}$, \\ RALF MATTHIAS HAGEN ${ }^{3}$ and HAGEN FRICKMANN ${ }^{4,5 *}$ ๑
}

\author{
${ }^{1}$ Department of Tropical Medicine and Infectious Diseases, Bundeswehr Hospital Hamburg, \\ Hamburg, Germany \\ ${ }^{2}$ German Federal Police, Potsdam, Germany \\ ${ }^{3}$ Department of Microbiology and Hospital Hygiene, Bundeswehr Central Hospital Koblenz, \\ Koblenz, Germany \\ ${ }^{4}$ Department of Microbiology and Hospital Hygiene, Bundeswehr Hospital Hamburg, Hamburg, \\ Germany \\ ${ }^{5}$ Institute for Medical Microbiology, Virology and Hygiene, University Medicine Rostock, Rostock, \\ Germany
}

Received: August 23, 2020 - Accepted: September 4, 2020

Published online: October 5, 2020

\begin{abstract}
Introduction: The study was performed to assess the infection risk of German police officers on predominantly tropical deployments, mostly United Nations missions, with gastrointestinal pathogens. Methods: Police officers were offered PCR-based screening for gastrointestinal pathogens before and after deployment. The screening panel comprised enteroinvasive bacteria (Salmonella spp., Shigella spp./enteroinvasive Escherichia coli, Campylobacter jejuni, and Yersinia spp.), enteropathogenic protozoa (Entamoeba histolytica, Giardia duodenalis, Cryptosporidium spp., and Cyclospora cayetanensis), as well as enteric helminths (Ancyclostoma spp., Ascaris lumbricoides, Enterobius vermicularis, Hymenolepis nana, Necator americanus, African Schistosoma spp., Strongyloides stercoralis, Taenia saginata, Taenia solium, and Trichuris trichiura). Results: G. duodenalis $(n=3)$, C. jejuni $(n=2)$, Salmonella spp. $(n=1)$, Shigella spp./enteroinvasive E. coli $(n=3)$, and S. stercoralis $(n=3)$ were detect in 12 out of $133(9.0 \%)$ police officers. The majority had shown gastrointestinal symptoms on deployment and all were asymptomatic at the time of medical assessment. The major infection sites were Sub-Saharan Africa followed by Northern Africa and the Middle East. Conclusions: Deployment of police officers to tropical deployment sites on United Nations missions is associated with a considerable acquisition risk of gastrointestinal pathogens in a quantitatively relevant minority. Post-deployment screening is advisable to facilitate therapeutic and hygiene-related consequences.
\end{abstract}

\section{KEYWORDS}

police, deployment, infectious disease, tropics, epidemiology, United Nations

\section{BACKGROUND}

*Corresponding author. Department of Microbiology and Hospital Hygiene, Bundeswehr Hospital Hamburg, Bernhard Nocht Str. 74, D-20359 Hamburg, Germany.

E-mail: Frickmann@bni-hamburg.de

Nearly a decade before, increased likelihood of enteric carriage with the intestinal protozoon Giardia duodenalis was demonstrated for German soldiers after deployment on a United Nations (UN) mission in tropical Sudan [1]. On this deployment, soldiers operating as UN observers lived outside traditional military field camp infrastructure, implying the need for buying food and beverages on local markets or for eating and drinking in local restaurants. These particular risks were identified to most likely account for the higher colonization or infection rate. 
Several reports on infectious disease-associated health risks on military UN missions can be found in international medical literature. Following the riots associated with the independence of the Democratic Republic of the Congo in 1960, an Austrian military medical team on an UN mission reported on relatively mild cases of malaria, severe amebic dysentery, and mild enteric helminth infections with Ascaris lumbricoides [2].

More recently, UN forces on a peace-keeping mission in Haiti reported infectious diseases predominantly associated with antimicrobial drug-resistant Enterobacteriaceae and with dengue fever virus in the late 1990s, while detected Plasmodium spp. were still susceptible to chloroquine at this time $[3,4]$.

Gastroenteritis on UN missions is of public health importance as demonstrated by a limited outbreak in Irish forces operating in South Eastern Chad from 2008 till 2010 [5] or frequent cases in British soldiers on a mission in South Sudan in 2017 as reported by the military medical surveillance software EPINATO 2 [6]. Of note, the British forces reported likely adaptation processes in the soldiers' gut, resulting in 3 times higher proportions of gastroenteritis in the first half of the operation compared with the second one [6]. In parallel, frequency of bites and stings was reduced to $50 \%$ as well, but while this phenomenon most likely resulted from experience and associated avoidance strategies, this is less likely for invisible risks like contamination due to diarrheagenic microorganisms. But also, complications like liver failure due to viral hepatitis A have to be considered as reported for a UN peacekeeper in South Sudan [7], stressing the importance of adequate vaccine protection.

Considerably less information is available on infectious disease risks in nonmilitary personnel during UN missions. In an assessment on medical evacuation and fatalities among civilian UN employees, infectious diseases were identified as a leading cause with $17 \%$ of the registered evacuations. Among the fatalities, infections accounted for even $41 \%$ [8]. Further, a Coxiella burnetii induced outbreak was recorded during UN deployment of Argentinean police forces in Kosovo [9].

Beyond such impressive outbreak events [9], however, little is known on endemic infectious health risks for police forces on UN deployment. Therefore, we have performed a retrospective assessment specifically addressing this topic based on molecular diagnostic screening results for deployed German police officers.

\section{PATIENTS AND METHODS}

\section{Population}

Since 2015, German police officers deployed to tropical UN missions were invited to provide stool samples for molecular diagnostic assessment on a voluntary basis prior as well as 8-12 weeks after deployment. The deployment periods, mainly ranged between less than a year and more than a year, during which the police officers usually lived in guarded compounds with local water supply and consumed food and beverages from local markets or in local restaurants. The screening was performed to provide both individual diagnostic results for therapeutic purposes and surveillance information for epidemiological risk assessments.

Clinical data provided on sample sheets of predeployment stool samples comprised age and sex of the patient as well as the history of previous deployments. Sample sheets of post deployment stool samples comprised data on age, sex, area, and duration of deployment, as well as more detailed information of gastrointestinal and febrile symptoms.

\section{Samples}

Voluntarily provided stool samples were sent by police physicians to the Department of Tropical Microbiology and Entomology of the Bundeswehr Hospital Hamburg, located at the Bernhard Nocht Institute for Tropical Medicine, Hamburg, which is the German National Reference Centre for Tropical Pathogens in Hamburg, Germany. As only DNA containing pathogens were assessed, sample storage and transport time of less than 6 weeks was still accepted, but usually the samples were transported within few days. Received stool samples were subjected to nucleic acid extraction using the QiaAMP DNA Stool Mini Kit (Qiagen, Hilden, Germany) as described by the manufacturer. Nucleic acid extractions were stored at $-80{ }^{\circ} \mathrm{C}$ prior to molecular assessment in batches once a month.

\section{Molecular assessment}

The nucleic acid extractions were subjected to in-house realtime multiplex PCR targeting enteroinvasive bacteria (Salmonella spp., Shigella spp./enteroinvasive Escherichia coli (EIEC), Campylobacter jejuni, and Yersinia spp.) [10], enteropathogenic protozoa (Entamoeba histolytica, G. duodenalis, Cyclospora cayetanensis, Cryptosporidium spp.) [11] as well as intestinal helminths (African Schistosoma spp., Ancylostoma spp., A. lumbricoides, Enterobius vermicularis, Hymenolepis nana, Necator americanus, Strongyloides stercoralis, Taenia saginata, Taenia solium, and Trichuris trichiura) [11]. PCR assay characteristics as calculated based on evaluation studies have been detailed elsewhere $[10,11]$.

\section{Inclusion and exclusion criteria}

Each stool sample fulfilling the minimum preanalytic standards as described above was included in the assessment. Lacking provision of pre-deployment stool samples was no exclusion for the analysis of post-deployment samples and vice versa, making several data sets incomplete. Incompletely filled sample sheets were no exclusion criteria as well.

\section{Statistics}

Due to the low total number of samples and patients, statistics were restricted to descriptive analysis.

\section{Ethics}

Ethical clearance (WF-019/17) for anonymous retrospective assessment without informed consent was obtained from the 


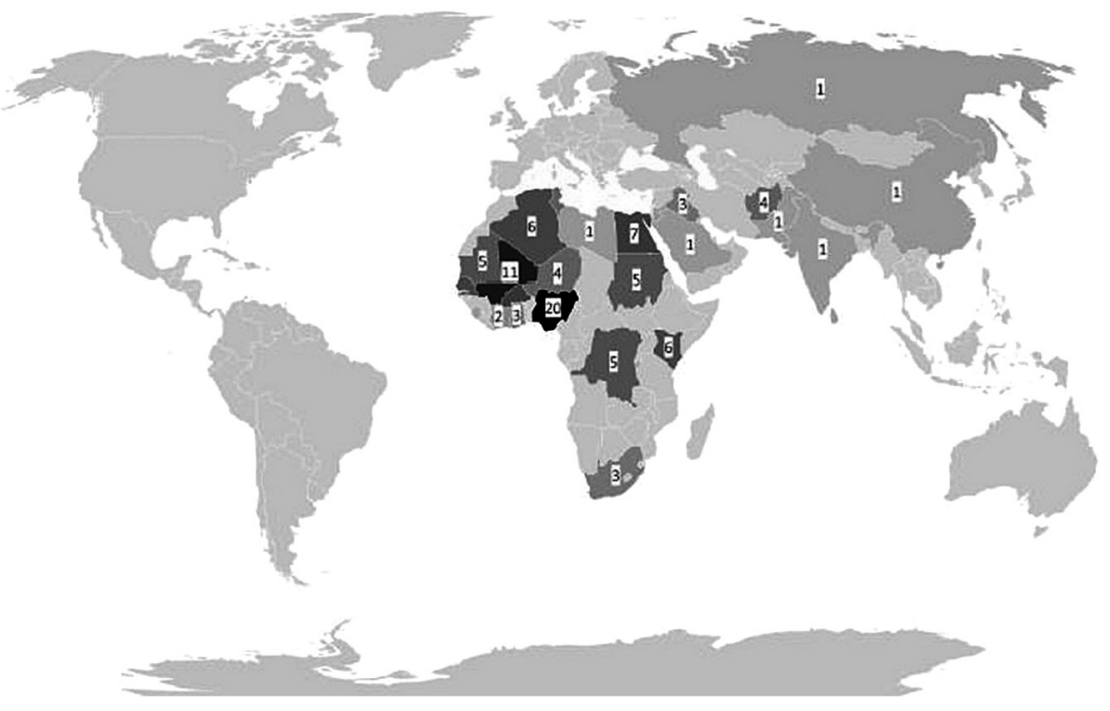

Fig. 1. Reported deployment sites of the police officers assessed in this study

Ethics Committee of the Medical Association of Hamburg, Germany, in line with German National Laws.

\section{RESULTS}

\section{Study population}

Between 2015 and 2020, a total of 133 deployed German police officers was included in the assessment. The mean age ( \pm standard deviation $(\mathrm{SD})$ ) was $43.1 \pm 8.6$, the median age was 45.0 in a right-shifted distribution. The male:female ratio was 12.3:1 ( $n=123$ males, $n=10$ females). Thereby, $62(46.6 \%)$ police officers provided pre-deployment stool samples, 71 (53.4\%) provided post-deployment stool samples. At total of 59 (44.4\%) provided both pre and postdeployment samples. The total number of assessed samples was 192 with 111 samples (57.8\%) provided after deployment. This higher number of samples compared with the number of assessed police officers results from multiple deployments of the same individuals. From the 62 officers who provided pre-deployment stool samples, 50 individuals (80.6\%) had reported previous deployments.

Associated with the 111 stool samples provided by police officers post-deployment, reported sites of deployment were Algeria $(n=6,5.4 \%)$, Afghanistan $(n=4,3.6 \%)$, Burkina Faso $(n=7,6.3 \%)$, Burundi $(n=1,0.9 \%)$, the Democratic Republic of the Congo ( $n=5,4.5 \%)$, Egypt ( $n=7,6.3 \%)$, Ghana $(n=2,1.8 \%)$, Iraq $(n=3,2.7 \%)$, Ivory Coast $(n=2$, $1.8 \%)$, Jordan $(n=1,0.9 \%)$, Kenya $(n=6,5.4 \%)$, Lebanon $(n=1,0.9 \%)$, Mali $(n=11,9.9 \%)$, Mauretania $(n=5$, $4.5 \%)$, Niger $(n=3,2.7 \%)$, Nigeria $(n=19,17.1 \%)$, Northern Africa (not further specified, $n=1,0.9 \%$ ), Pakistan $(n=1,0.9 \%)$, Russia $(n=1,0.9 \%)$, Saudi Arabia $(1,0.9 \%)$, Senegal $(6,5.4 \%)$, Sierra Leone $(n=1,0.9 \%)$, South Africa $(n=3,2.7 \%)$, Sudan $(n=5,4.5 \%)$, Tunisia $(n$ $=3,2.7 \%)$, or multiple countries $(n=3,2.7 \%$; case 1 : Libya, Niger, and Tunisia; case 2: China, India, and Sri Lanka; case
3: Ghana, and Nigeria), while no sites of deployment were reported in 3 instances. A visualization of the sites of deployment is shown in Fig. 1.

Duration of stay ranged from $<1$ week $(n=1,0.9 \%)$ about $1-4$ weeks-intervals $(n=1,0.9 \%)$ up to longer deployments $>4$ weeks $(n=107,96.4 \%)$, while no data were provided in two instances $(n=2,1.8 \%)$. Occurrences of gastrointestinal symptoms on deployment were reported by $40(36.0 \%)$ of the police officers, after deployment by $0(0 \%)$ and not at all by 62 (55.9\%), while 9 individuals (8.1\%) did not answer this question. Reported stool frequency was once or twice a day in $36(32.4 \%)$ cases and $\geq 3$ times a day (in line with standard definitions of diarrhea and associated with unformed stool) in $19(17.1 \%)$ cases. Details on reported symptoms comprised visible blood in stool in $0(0 \%)$ cases, stomach ache in $15(13.5 \%)$ cases, nausea and vomiting in 14 $(12.6 \%)$ cases, cramps in $6(5.4 \%)$ cases, severe flatulence in $12(10.8 \%)$ cases, and fever defined as body temperature $\geq 38.5{ }^{\circ} \mathrm{C}$ (degree centigrade) in $11(9.9 \%)$ cases. Reported duration of gastrointestinal symptoms ranged from $\leq 1$ week in $25(22.5 \%)$ cases to more than a week in $10(9.0 \%)$ cases. In spite of diarrhea, none of the policmen consultated a physician on deployment. Also, the police officers did not report any medication at the time of the stool analysis.

\section{Detected pathogens}

The following pathogens were detected by PCR in the stool of the assessed police officers: G. duodenalis $(n=3), C$. jejuni $(n=2)$, Salmonella spp. $(n=1)$, Shigella spp./ enteroinvasive E. coli $(n=3)$, and S. stercoralis $(n=3)$. With the exception of one case with $S$. stercoralis in a predeployment assessment of a police officer with previous deployments to not-reported deployment sites, all other pathogens were detected in post-deployment assessments.

In total, 12 out of 133 police officers (9.0\%) were affected by a pathogen, while abundance of multiple pathogens was not observed. The geographical distribution of pathogen 
acquisition is shown in Table 1 , indicating local predominance of infection events in Sub-Saharan Africa followed by North Africa and the Middle East. Focusing on the reported symptoms, the association between pathogens and symptoms is presented in Table 2. As shown in this table, mild to moderate gastrointestinal symptoms on deployment were frequently but not always reported by police officers with proven gastrointestinal pathogens. Of note, these symptoms never facilitated consultations of a physician for diagnostic work-up or therapeutic intervention.

\section{DISCUSSION}

Dominance of gastrointestinal infections among infectious diseases observed on tropical deployments is well known from military operations [12-14]. For civilian Western travelers, a similar importance of enteric pathogens has been demonstrated by assessments of the GEOSENTINEL database [15]. Not surprisingly, deployed police officers are no exception as shown by a considerable enteric infection and infestation rate in this study.

Regarding the predominantly identified pathogens, bacteria dominated followed by enteric parasites, which is perfectly in line with previous reports on infectious gastroenteritis in the Sub-Saharan tropics associated with living under hygiene-restricted, local conditions [16, 17]. In particular, the abundance of $G$. duodenalis matches similar

Table 1. Presumed sites of pathogen acquisition on deployment

\begin{tabular}{|c|c|}
\hline Pathogen (number $n$ ) & $\begin{array}{l}\text { Area of deployment (number } \\
n, \% \text { of all returnees from the } \\
\text { respective area of deployment) }\end{array}$ \\
\hline Campylobacter jejuni $(n=2)$ & Afghanistan $(2 / 4,50.0 \%)$ \\
\hline Giardia duodenalis $(n=3)$ & $\begin{array}{c}\text { Burkina Faso (1/7, 14.3\%); } \\
\text { Kenya }(1 / 6,16.7 \%) \text {; Nigeria (1/ } \\
19,5.3 \%)\end{array}$ \\
\hline Salmonella spp. $(n=1)$ & Egypt $(1 / 7,14.3 \%)$ \\
\hline $\begin{array}{l}\text { Shigella spp./enteroinvasive } \\
\text { Escherichia coli }(n=3)\end{array}$ & Mali $(3 / 11,27.3 \%)$ \\
\hline Strongyloides stercoralis $(n=3)$ & $\begin{array}{c}\text { Iraq }(1 / 3,33.3 \%), \text { Nigeria }(1 / 19, \\
5.3 \%), \text { pre-deployment }(1 / 81, \\
1.2 \%)\end{array}$ \\
\hline
\end{tabular}

previous experience with German soldiers on United $\mathrm{Na}$ tions missions quite well [1].

Focusing on the observed symptoms, the most affected police officers had reported any gastrointestinal symptoms on deployment; however, those were nonspecific and had spontaneously vanished after deployment. No-one reported any consultations of physicians due to gastrointestinal symptoms. In line with this, the pathogen detections would highly likely have been missed without the police officers' voluntary participation in the screening. This may be acceptable in case of bacterial infections, in case of which spontaneous decolonization can be awaited in asymptomatic patients if there are no hygiene-related contraindications. In support of this assumption, previous studies have shown high rates of spontaneous clearance of enteric colonization with multidrug-resistant bacteria which were acquired on travel abroad after the return [18, 19]. However, at least counseling on appropriate hygiene strategies for the prevention of the fecal-oral spread between the family members at home is advisable in such situations. In case of the detected enteric protozoa, however, antimicrobial therapy should be performed. Further, in line with the German Infection Prevention Act (Infektionsschutzgesetz, IfSG), with the exception of $S$. stercoralis, all detected pathogens from this study were notifiable to the local health authority due to hygiene considerations.

Regarding the reported areas of presumed infection, the deployment sites were predominantly located in SubSaharan Africa, followed by Northern Africa and the Middle East. Again, the pathogen spectrum matches the results from previous studies in Sub-Saharan Africa well $[16,17]$. Just in one instance of a $S$. stercoralis infestation, the likely area of infection on a previous deployment could not be retrospectively identified.

Asymptomatic infections and infestations may occur as observed in this study as well, making it challenging to distinguish colonization from infection events [20]. This phenomenon is especially pronounced for local inhabitants of resource-limited tropical areas [16], making the development of some sort of semi-immunity likely in the course of long-term stays on such deployments. Previous reports on reduced frequencies of gastrointestinal disease in later stages of deployments are likely to support this hypothesis [6] and match well with the observation from our study that gastrointestinal symptoms were not observed after

Table 2. Association between pathogens and symptoms

\begin{tabular}{|c|c|c|c|}
\hline Pathogen (number $n$ ) & $\begin{array}{l}\text { Any symptoms reported } \\
\text { (percentage) }\end{array}$ & $\begin{array}{l}\text { Details of reported symptoms } \\
\text { (including fever) }\end{array}$ & $\begin{array}{l}\text { Consultation of a physician } \\
\text { and/or medical treatment due } \\
\text { to gastroenteritis (number } n \text { ) }\end{array}$ \\
\hline Giardia duodenalis $(n=3)$ & $2 / 3(66.7 \%)$ & $\begin{array}{l}\text { Diarrhea, abdominal pain, } \\
\text { nausea, fever, cramps }\end{array}$ & $0(0.0 \%)$ \\
\hline Salmonella spp. $(n=1)$ & $0 / 1(0.0 \%)$ & Not applicable & $0(0.0 \%)$ \\
\hline Strongyloides stercoralis $(n=3)$ & $1 / 3(33.3 \%)$ & Diarrhea & $0(0.0 \%)$ \\
\hline
\end{tabular}


deployment in the police officers in spite of pathogen detections by PCR.

The study has some undeniable limitations. First, the number of assessed police officers over 5 years is still low and only a minor proportion provided both pre-deployment and post-deployment stool samples. Secondly, the assessment is retrospective, further limiting its interpretability. Thirdly, the information on the sample sheets was in part incomplete. Taking those limitations together, the results of the study have to be considered as preliminary and hypothesis-forming. Future prospective studies are desirable to further assess specific health risks for police officers on tropical deployments.

\section{CONCLUSIONS}

In spite of the limitations mentioned above, the study indicates a quantitatively relevant minority of infected and infested police officers after tropical deployments. Targeted screening for tropical infectious diseases is therefore advisable as a routine procedure. Further, prospective epidemiological research on police officers on deployment in resource-limited tropical areas with restricted hygiene conditions may provide better understanding of specific health risks associated with such deployments. In addition, the results suggest a need for compensating the risk for enteric infections due to exposition in endemic regions by specific training and education of the risk personnel concerning hygiene measures and basics of infectious diseases.

Funding sources: No financial support was received for this study.

Authors' contribution: $\mathrm{MH}, \mathrm{UM}, \mathrm{RMH}$ and $\mathrm{HF}$ jointly planned the study. $\mathrm{MH}$ assessed the data and prepared the manuscript. All authors have jointly optimized and reviewed the manuscript.

Conflict of interest: Nothing to declare.

\section{ACKNOWLEDGMENT}

Nancy Lindenberg is gratefully acknowledged for excellent assistance regarding the data management.

\section{REFERENCES}

1. Frickmann H, Schwarz NG, Wiemer DF, Fischer M, Tannich E, Scheid PL, et al. Food and drinking water hygiene and intestinal protozoa in deployed German soldiers. Eur J Microbiol Immunol (Bp) 2013;3:53-60.

2. Pervulesko W. Commitment of Austrian medical contingents in the police action of the United Nations in the Congo. Tropical Medical
Remarks. Wien Med Wochenschr 1963;113:896-900. [Article in German].

3. Drabick JJ, Gambel JM, Huck E, De Young S, Hardeman L. Microbiological laboratory results from Haiti: June-October 1995. Bull World Health Organ 1997;75:109-25.

4. Rossi CA, Drabick JJ, Gambel JM, Sun W, Lewis TE, Henchal EA. Laboratory diagnosis of acute dengue fever during the United Nations Mission in Haiti, 1995-1996. Am J Trop Med Hyg 1998;59: 275-8.

5. Hickey JP. Provision of healthcare in a remote base of operations in southern Chad. Travel Med Infect Dis 2010;8:292-301.

6. Bonham CT, Pallett SJC, Holland TJ. OP TRENTON 3: An analysis of primary care presentations to a deployed role 1 in support of a United Nation peacekeeping operation. J R Army Med Corps 2019. [Epub ahead of print]. https://doi.org/10.1136/ jramc-2019-001203.

7. Li C, Su H, Hu J, Duan H, Ji J. Case of severe acute hepatitis A virus infection in United Nations peacekeepers in South Sudan. J R Army Med Corps 2019;165:198-200.

8. Peytremann I, Baduraux M, O'Donovan S, Loutan L. Medical evacuations and fatalities of United Nations High Commissioner for Refugees field employees. J Travel Med 2001;8: $117-21$.

9. Faas A, Engeler A, Zimmermann A, Zöller L. Outbreak of query fever among Argentinean special police unit officers during a United Nations mission in Prizren, South Kosovo. Mil Med 2007; 172:1103-6.

10. Wiemer D, Loderstaedt U, von Wulffen H, Priesnitz S, Fischer M, Tannich E, et al. Real-time multiplex PCR for simultaneous detection of Campylobacter jejuni, Salmonella, Shigella and Yersinia species in fecal samples. Int J Med Microbiol 2011;301: 577-84.

11. Köller T, Hahn A, Altangerel E, Verweij JJ, Landt O, Kann S, et al. Comparison of commercial and in-house real-time PCR platforms for 15 parasites and microsporidia in human stool samples without a gold standard. Acta Trop 2020;207: 105516.

12. Frickmann H, Warnke P, Frey C, Schmidt S, Janke C, Erkens K, et al. Surveillance of food- and smear-transmitted pathogens in European soldiers with diarrhea on deployment in the tropics: Experience from the European Union Training Mission (EUTM) mali. Biomed Res Int 2015;2015:573904.

13. Frickmann H, Hagen RM, Geiselbrechtinger F, Hoysal N. Infectious diseases during the European Union training mission Mali (EUTM MLI) - A four-year experience. Mil Med Res 2018;5:19.

14. Murray CK, Yun HC, Markelz AE, Okulicz JF, Vento TJ, Burgess $\mathrm{TH}$, et al. Operation United Assistance: Infectious disease threats to deployed military personnel. Mil Med 2015;180: 626-51.

15. Jensenius M, Han PV, Schlagenhauf P, Schwartz E, Parola P, Castelli F, et al. GeoSentinel Surveillance Network. Acute and potentially life-threatening tropical diseases in western travelers-a GeoSentinel multicenter study, 1996-2011. Am J Trop Med Hyg 2013;88:397-404.

16. Krumkamp R, Sarpong N, Schwarz NG, Adlkofer J, Loag W, Eibach $\mathrm{D}$, et al. Gastrointestinal infections and diarrheal disease in 
Ghanaian infants and children: an outpatient case-control study. PLoS Negl Trop Dis 2015;9:e0003568.

17. Eibach D, Krumkamp R, Hahn A, Sarpong N, Adu-Sarkodie Y, Leva A, et al. Application of a multiplex PCR assay for the detection of gastrointestinal pathogens in a rural African setting. BMC Infect Dis 2016;16:150.

18. Ruppé E, Armand-Lefêvre L, Estellat C, Consigny PH, El Mniai A, Boussadia $\mathrm{Y}$, et al. High rate of acquisition but short duration of carriage of multidrug-resistant Enterobacteriaceae after travel to the tropics. Clin Infect Dis 2015;61:593-600.
19. Arcilla MS, van Hattem JM, Haverkate MR, Bootsma MCJ, van Genderen PJJ, Goorhuis A, et al. Import and spread of extendedspectrum $\beta$-lactamase-producing Enterobacteriaceae by international travellers (COMBAT study): a prospective, multicentre cohort study. Lancet Infect Dis 2017;17:78-85.

20. Zautner AE, Groß U, Emele MF, Hagen RM, Frickmann H. More pathogenicity or just more pathogens? - On the interpretation problem of multiple pathogen detections with diagnostic multiplex assays. Front Microbiol 2017;8:1210. 